\title{
An Investigation and Comparison of Strength against the Compressive loads (Static and Dynamic) in 4 Iranian, Chinese, Uzbek, and Turkmen Types of Silk Used in Iran's Hand-woven Carpets
}

\author{
Behzad Nikandish \\ Master student of Carpet, Kashan University \\ Gholamreza Saleh Alavi \\ Corresponding author, Faculty member of Carpet Department, Kashan University \\ Email: Gr.salehalavi@gmail.com
}

\begin{abstract}
The silk yarns are mostly used in carpet's piles. Among the important attributes of the yarns used in the carpet's piles is the strength against the static and dynamic load. In the current study, three woven samples from each of the four types as Iranian, Chinese, Turkmen, and Uzbek silks were extracted and through the required tests, the above-mentioned attributes were investigated and compared for them. The results indicate that against the static loads, the Chinese silk has the highest strength, and the Uzbek and Iranian silks are next, with a narrow difference. The Turkmen is ranked last in terms of strength. Also, the Iranian silk did best in strength against the dynamic loads, and it had the highest strength, with the Turkmen, Chinese, and Uzbek silks being after it with a marginal difference. The current study is conducted by the use of documentary and laboratory methods.
\end{abstract}

Keywords: Silk, hand-woven carpet, Strength against static load, Strength against the dynamic load.

\section{1- Introduction:}

The silk yarns have been long used in the production of beautiful and precious fabrics. These yarns, due to their unique attributes, are being used in many other industries. The most important use of silk in Iran is the handwoven silk carpets. Currently, this silk product, which is also traded in the international markets, uses more than 95\% of the silk in Iran [1 and 2].

Recently, due to several reasons, silk production in Iran has been reduced and the silk carpet producers have turned to use imported silk.

Through the field investigation on the Iranian silk market and the statistics provided by Tehran Chamber of Commerce, it is revealed that the silk has been mostly imported from China, Uzbekistan, and Turkmenistan, in the recent years [3].

Regarding the direct relationship between the quality of silk thread and the quality of the final product, it is necessary to sufficiently investigate and recognize the quality attributes of the types of the silk used in the silk carpets, especially the attributes of the threads that are more important in the carpet. One of the important attributes of the pile's threads used in the carpeting is their strength against the static and dynamic compressive loads [4].

The lack of strength against the compressive loads would lead to the disruption in all the elements of the carpet and adversely affects their desired attributes, however, the first phenomenon that happens is the bending of the piles and deformity in the carpet's appearance as well as the distortion of its design and pattern. And, the carpets are dismissed most of the times due to losing their beauty, rather than losing other attributes.

Therefore, the current study is aimed at investigation and comparison of the strength against static and dynamic loads between the four types of silk as Iranian, Chinese, Uzbek, and Turkmen silks.

Regarding the effects of the type of the yarn on carpet strength against the compressive loads, several studies have been conducted in the field of hand-woven and machine carpets, such as the followings:

Mirjalili and Sharzehi, in a study conducted on the hand-woven carpets, collected two types of wool as the normal and tanned wool collected from two famous regions in Iran, namely Sirjan and Kermanshah, and weaved carpet samples from these wool types with 25 and 35 rows in a $6.5 \mathrm{~cm}$ knot. Then, they put the samples under static load and after omitting the static load, they measured the changes in the thickness of the samples in different time periods. The results obtained by them indicate that: 
Time is the most important factor in the reduction of the thickness of the samples.

The reduction in the knotted samples thickness was higher in the wool collected from Sirjan (both the normal and the tanned wool) compared to Kermanshah's wool.

The knot density is another factor effective on the carpet's pile resilience.

Contrary to the public opinion, the quality of the carpets woven by the tanned wool is not only lower than the normal wool, but also, most of the times, they are the same [5].

GhareAghaji and Moghsem in a study investigated the effects of knot density and pile height on the behavior of hand-woven carpet under compressive load. They collected three types of wool, namely the normal wool, the tanned wool, and a mix of tanned and normal wools, obtained from the Nayini sheep species, however, each of the carpet samples was put under the compressive loads in three different pile height and two knot density.

The results obtained by them indicate that:

The increase in tanned wool percentage leads to the increase in density and piles decumbency, and the decrease in elastic resilience of the pile thread.

The increase in the knot density per unit of carpet's surface would lead to the decrease in density percentage and piles decumbency, and the increase in piles elastic resilience percentage [6].

Koc in his study put different samples of machine carpet with different yarns under a fixed compressive load and measured the changes in carpet's thickness after the removal of the load over time. His results indicated that:

The type of the yarns, their number per thread's section, and the pile height have been effective on the piles' resilience [7].

Erdogan, in a study, investigated the effects of piles yarns cross-section shape on the density behavior. He put carpet samples woven from BCF thread (Polypropylene) with hollow circular sections (PP-H) and triangular section (TRiloBal, PP-T) under static load. It should be noted that other weaving parameters were completely the same. The results indicated that:

The PP-H's sample lost thickness percentage was a bit higher than the sample woven from PP-T.

In the short-term loading, the density percentage of PP-T sample was higher than that of PP-H sample, however, for the long-term loading, the opposite is true [8].

Indeed, numerous studies have been done on the effects of other factors on the carpet strength against the compressive loads, but the type of yarn intended by the researcher, has not been addressed. Some of these studies are as follows:

Caranby has researched the carpet behaviors such as the changes in its thickness or its piles bending under the compressive loads. He has put a bunch of spun woolen yarns under a compressive load and has drawn the yarn bunch behavior curve by the use of Instron equipment [9].

K.dubinsKaite also has studied the carpet behavior under compressive loads on samples of machine carpet woven by the wool-polyamide mixed thread. He has evaluated two structural parameters (height and pile density) on the behavior of the carpet under the compressive load [10].

YaseminKorkmaz et al. collected samples of machine carpets woven by the acrylic threads in 1600 and 2400 piles per square meter density and piles heights of $9,10,12.5$, and $14 \mathrm{~mm}$, and put them under short- and longterm compressive loads, evaluating their density behaviors [11].

Totally, the studies conducted so far indicate that the type of yarns (material, diameter, and the cross-section shape) is effective on the behavior of the carpet under the compressive loads.

\section{2- Methods and Materials:}

\section{2-1- Materials:}

\section{Piles Threads:}

In order to weave the sample carpets, the pile thread (Khabi) made of four types of silks from Iran, China, Turkmenistan, and Uzbekistan, whose numbers, according to the tests, were 4.7, 5.5, 8, and 9.1 metrics respectively, were used.

\section{Warp and Weft Threads:}

The warp and weft used for the carpet were made of cotton and their numbers are as follows:

The number of warp threads in Iranian and Chinese carpet samples was Ne 20/12

The number of warp threads in Turkmen and Uzbek carpet samples was Ne 20/9

The number of thick weft threads in Iranian and Chinese carpet samples was Ne 10/12

The number of thick weft threads in Turkmen and Uzbek carpet samples was Ne 10/9 
The number of the thin weft threads used in all samples was Ne 20/3.

The threads used in the samples were all obtained from Kashan market.

\section{2-2- The Equipment Used:}

In order to do the experiments, the facilities and equipment present in the laboratories of the Carpet Department of Kashan University were used. The device's specifications are as follows:

- $\quad$ GF300 Digital scale with precision 0.001 grams, made in Japan

- $\quad$ Yarn strength tester machine made by Rees Sanj Co., in Iran

- $\quad$ Electronic twist tester made by Rees Sanj Co., in Iran

- $\quad$ Thickness tester made by Rees Sanj Co., in Iran

- $\quad$ Static loading machine model P5086353 made by Shirley Co., in England

- $\quad$ Dynamic loading machine made by Rees Sanj Co., in Iran

\section{2-3- samples Production:}

Since the strength against the compressive loads, in addition to being affected by the type of pile, is also affected by the pile's length and density of the carpet, the pile's length is set equal for all the samples, regarding the fact that the carpet's density, according to the equation $\mathrm{Pd}=(\mathrm{n} \times 2) /(\mathrm{Nm} \times 1000)$, depends on the number of rows and the pile thread score [12].

And because the scores of silk pile threads from different countries were different, in order to reach the same density, the row count of 39 for the Iranian sample, the row count of 42 for the Chinese sample, the row count of 51 for the Turkmen sample, and the row count of 54 for the Uzbek sample, were considered. From each type of the silks, 4 samples of $10 \times 10 \mathrm{~cm}$ were woven. In weaving the samples, the Turkish knot and the hand-looming technique was used. The specifications of the carpets are provided in table 2-1.

Table 2-1: the technical specifications of the samples woven from the different types of silk

\begin{tabular}{|c|c|c|c|c|c|c|c|c|}
\hline Silk yarn & $\begin{array}{l}\text { The pile thread } \\
\text { material and its } \\
\text { number) } \mathrm{Nm} \text { ( }\end{array}$ & $\begin{array}{c}\text { The warp } \\
\text { thread } \\
\text { material } \\
\text { and its } \\
\text { number } \\
\text { )Ne( }\end{array}$ & $\begin{array}{l}\text { The bottom } \\
\text { weft } \\
\text { material and } \\
\text { its number } \\
\text { )Ne( }\end{array}$ & $\begin{array}{c}\text { The top weft } \\
\text { material and } \\
\text { its number } \\
\text { )Ne( }\end{array}$ & $\begin{array}{l}\text { The } \\
\text { row } \\
\text { count } \\
\text { 5)cm } \\
6 .(\end{array}$ & $\begin{array}{l}\text { Khab's } \\
\text { mean } \\
\text { height } \\
(\mathrm{mm})\end{array}$ & Knot type & $\begin{array}{c}\text { Weaving } \\
\text { method }\end{array}$ \\
\hline Iranian & Iranian Silk4/7 & $\begin{array}{l}12 \text {-ply } \\
\text { cotton } 20\end{array}$ & $\begin{array}{l}\text { 10-ply } \\
\text { cotton } 10\end{array}$ & $\begin{array}{l}3 \text {-ply cotton } \\
20\end{array}$ & 39 & $6 / 65$ & Turkish & $\begin{array}{l}\text { Hand- } \\
\text { loomed }\end{array}$ \\
\hline Chinese & $\begin{array}{l}\text { Chinese Silk } \\
5 / 5\end{array}$ & $\begin{array}{l}\text { 12-ply } \\
\text { cotton } 20\end{array}$ & $\begin{array}{l}\text { 12-ply } \\
\text { cotton } 10\end{array}$ & $\begin{array}{l}3 \text {-ply cotton } \\
20\end{array}$ & 42 & $7 / 19$ & Turkish & $\begin{array}{l}\text { Hand- } \\
\text { loomed }\end{array}$ \\
\hline Turkmen & $\begin{array}{ll}\text { Turkmen } & \text { Silk } \\
8 & \end{array}$ & $\begin{array}{l}\text { 9-ply } \\
\text { cotton } 20\end{array}$ & $\begin{array}{l}\text { 9-ply cotton } \\
10\end{array}$ & $\begin{array}{l}\text { 3-ply cotton } \\
20\end{array}$ & 51 & $6 / 61$ & Turkish & $\begin{array}{l}\text { Hand- } \\
\text { loomed }\end{array}$ \\
\hline Uzbek & Uzbek Silk9/1 & $\begin{array}{l}9 \text {-ply } \\
\text { cotton } 20\end{array}$ & $\begin{array}{l}\text { 9-ply cotton } \\
10\end{array}$ & $\begin{array}{l}\text { 3-ply cotton } \\
20\end{array}$ & 54 & $6 / 63$ & Turkish & $\begin{array}{l}\text { Hand- } \\
\text { loomed }\end{array}$ \\
\hline
\end{tabular}

\section{2-4- Experiment Method:}

The samples, including the threads and the carpets, were placed in a standard environment prior to the experiment (in accordance with the standard No. 948) [13].

The necessary experiments done on the threads used for weaving the samples were conducted in accordance with the common standards, which are not to be elaborated here. However, the experiments were done on the samples in the following methods.

\section{- Measuring the Strength against the Static Load:}

This experiment is aimed at measuring the rate of the decrease in carpet thickness under the static load. This experiment, as instructed by the device manufacturer, was conducted as follows. The device has a 10kg movable weight. After measuring the thickness of the samples, and putting them between two $10 \times 10 \mathrm{~cm}$ aluminum plates, and placing the related pedal on it, we hang the $10 \mathrm{~kg}$ weight for application of the load.

After 24 hours of applying the load, the sample is taken out and its thickness is measured by the thickness tester machine.

After a 2-minute rest, an hour rest, and 25-hour rest, the thickness of the samples was measured, to be provided in the related table, and the drawn as a chart. 


\section{- Measuring the Strength against the Dynamic Load:}

This experiment was aimed at measuring the rate of the decrease in carpet thickness under the dynamic load.

This experiment also was conducted according to the instructions provided by the device manufacturer. The sample is put under a mobile load through a weight. This weight has two legs on its two edges, which land repeatedly on the sample freely. The sample slowly moves in a way that the vertical cut force which is applied by the lower edges of the weight on a specified section of the sample.

In this experiment, the number of the hits on the sample is considered as 500 hits, and the sample thickness is measured after every 50 hits. The difference in the sample thickness compared to its thickness prior to the experiment indicates that in each period, the thickness is reduced. The obtained numbers are shown in the table and drawn as a chart.

\section{- Measuring the Samples Thickness:}

In order to measure the changes in samples thickness, which is indicative of their strength against the compressive loads, their thickness prior to and after the experiments, should be measured.

It is done by a digital thickness tester. This test has been conducted in accordance with the standard 889 [14].

\section{3- Discussion and Conclusion:}

\section{3-1- Evaluation of the Samples Strength against the Static Load:}

Three samples were woven and tested from each type of silk. The method of the experiment was that the sample, 24 hours prior to conducting the initial thickness test, were put in the laboratory environment, and then, the initial thickness was measured. Then, the sample was put under load for 24 hours and the thickness was measured again. After that, the samples rested for two minutes, and their thickness was re-measured. In the following, the samples rested for another hour to be measured again. For a third time, the samples rested for 24 hours, and their thickness was noted down. The results are provided in table 3-1, and the charts 3-1, 3-2, 3-3, and 3-4.

Table 3-1: the samples mean thickness

\begin{tabular}{|c|c|c|c|c|c|}
\hline Silk type & $\begin{array}{c}\text { Initial } \\
\text { thickness }\end{array}$ & $\begin{array}{c}\text { Thickness instantly } \\
\text { after load removal }\end{array}$ & $\begin{array}{c}\text { Thickness after } \\
\text { a 2-minute rest }\end{array}$ & $\begin{array}{c}\text { Thickness after } \\
\text { an hour rest }\end{array}$ & $\begin{array}{c}\text { Thickness after } \\
\text { a 24-hour rest }\end{array}$ \\
\hline Iranian silk & $6 / 65$ & $5 / 94$ & $6 / 16$ & $6 / 25$ & $6 / 44$ \\
\hline Chinese silk & $7 / 19$ & $6 / 72$ & $6 / 86$ & $6 / 98$ & $7 / 06$ \\
\hline Turkmen silk & $6 / 61$ & $5 / 70$ & $5 / 83$ & $5 / 89$ & $5 / 99$ \\
\hline Uzbek silk & $6 / 63$ & $5 / 98$ & $6 / 14$ & $6 / 29$ & $6 / 48$ \\
\hline
\end{tabular}

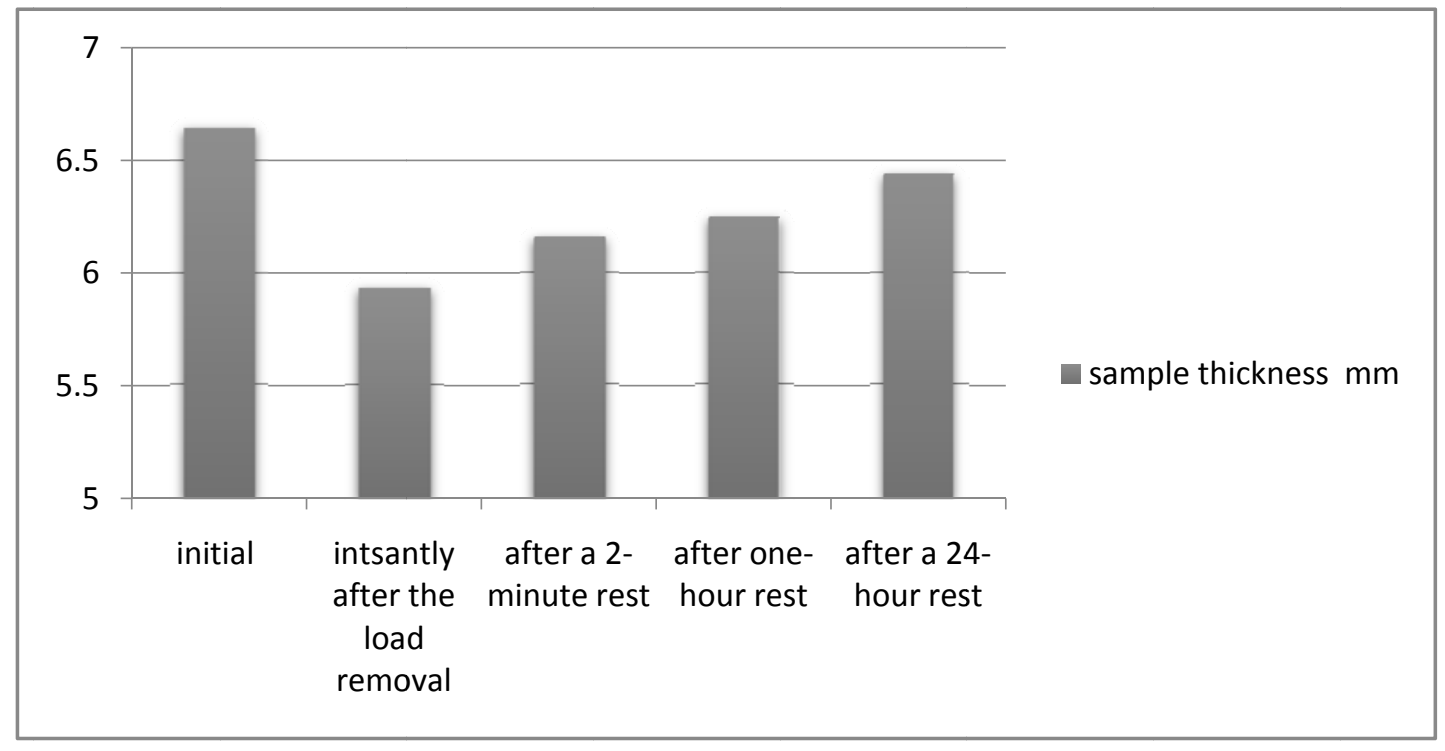

Chart 3-1: thickness measurement of Iranian silk under the static load 
The mean thickness of samples woven from the Iranian silk was $6.65 \mathrm{~mm}$ prior to the experiment, which was decreased to $5.94 \mathrm{~mm}$ after the application of force for 24 hours. At this stage, $0.71 \mathrm{~mm}$ of the sample thickness was reduced (about 10.67\%). After two minutes of rest, the sample thickness was measured as $6.16 \mathrm{~mm}$, which means that $0.22 \mathrm{~mm}$ of the thickness was recovered, and the difference between the prior-to-experiment thickness and the current thickness reached to $0.49 \mathrm{~mm}$.

The mean thickness in the sample woven from the Iranian silk reached $6.25 \mathrm{~mm}$ after one hour, which shows a $0.4 \mathrm{~mm}$ difference with the initial thickness. At this stage, $0.09 \mathrm{~mm}$ was added to the initial thickness, compared to the previous stage.

After 24 hours of rest, the sample thickness became $6.44 \mathrm{~mm}$, which was $0.19 \mathrm{~mm}$ higher than the previous stage thickness, and $0.21 \mathrm{~mm}$ higher than the initial thickness. Regarding the obtained means, it can be concluded that in these samples, about $0.21 \mathrm{~mm}$ (about $3.15 \%$ ) of the initial thickness has not been recovered.

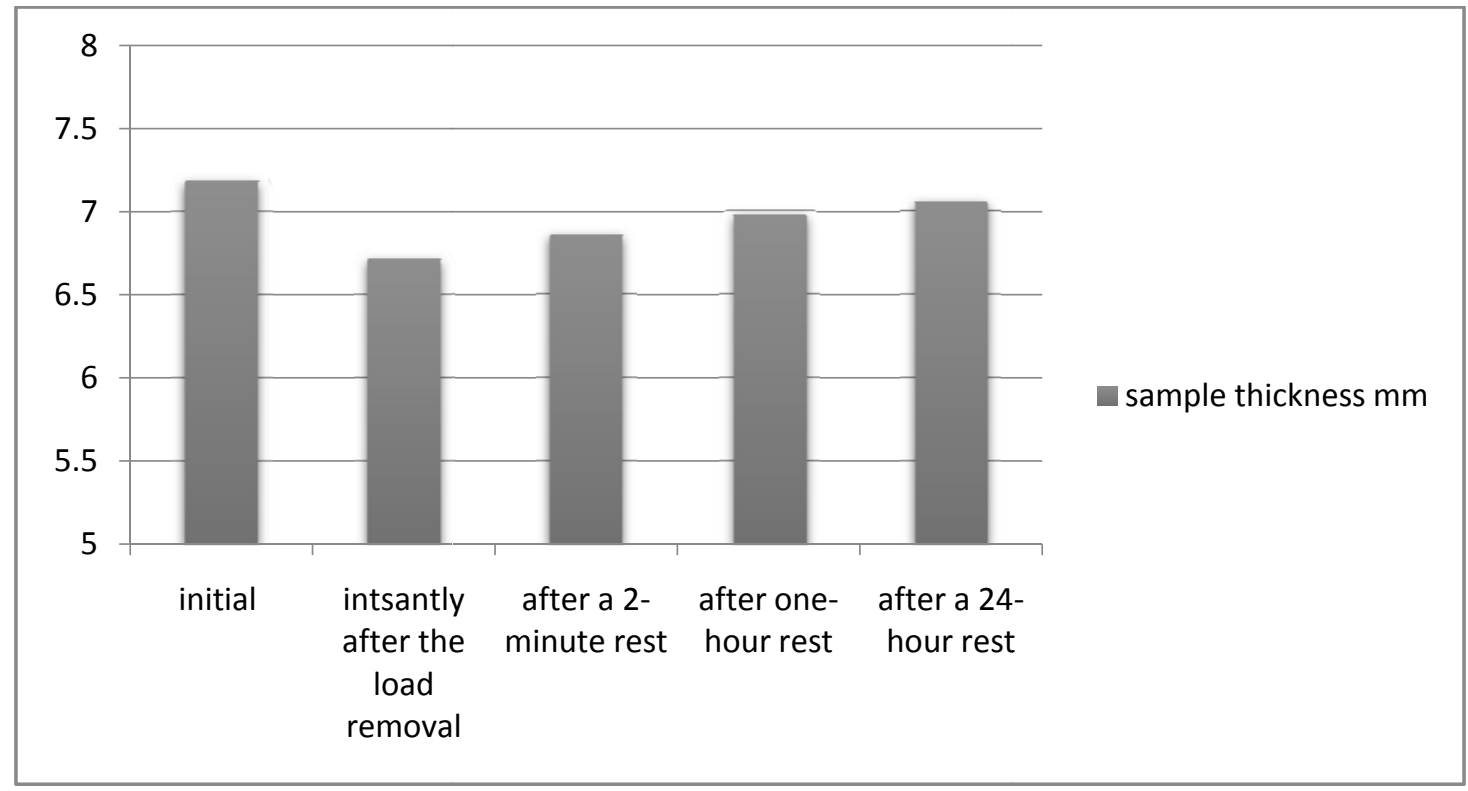

Chart 3-2: thickness measurement of Chinese silk under the static load

The mean thickness of samples woven from the Chinese silk was $7.19 \mathrm{~mm}$ prior to the experiment, which was decreased to $6.72 \mathrm{~mm}$ after the application of force for 24 hours. At this stage, $0.47 \mathrm{~mm}$ of the sample thickness was reduced (about 6.53\%). After two minutes of rest, the sample thickness was measured as $0.14 \mathrm{~mm}$, which means that $0.33 \mathrm{~mm}$ of the thickness was recovered, and the difference between the prior-to-experiment thickness and the current thickness reached to $0.49 \mathrm{~mm}$.

The mean thickness in the sample woven from the Chinese silk reached $6.98 \mathrm{~mm}$ after one hour, which shows a $0.21 \mathrm{~mm}$ difference with the initial thickness. At this stage, $0.12 \mathrm{~mm}$ was added to the initial thickness, compared to the previous stage.

After 24 hours of rest, the sample thickness became $7.06 \mathrm{~mm}$, which was $0.08 \mathrm{~mm}$ higher than the previous stage thickness, and $0.13 \mathrm{~mm}$ lower than the initial thickness. Regarding the obtained means, it can be concluded that in these samples, about $0.13 \mathrm{~mm}$ (about $1.8 \%$ ) of the initial thickness has not been recovered. 


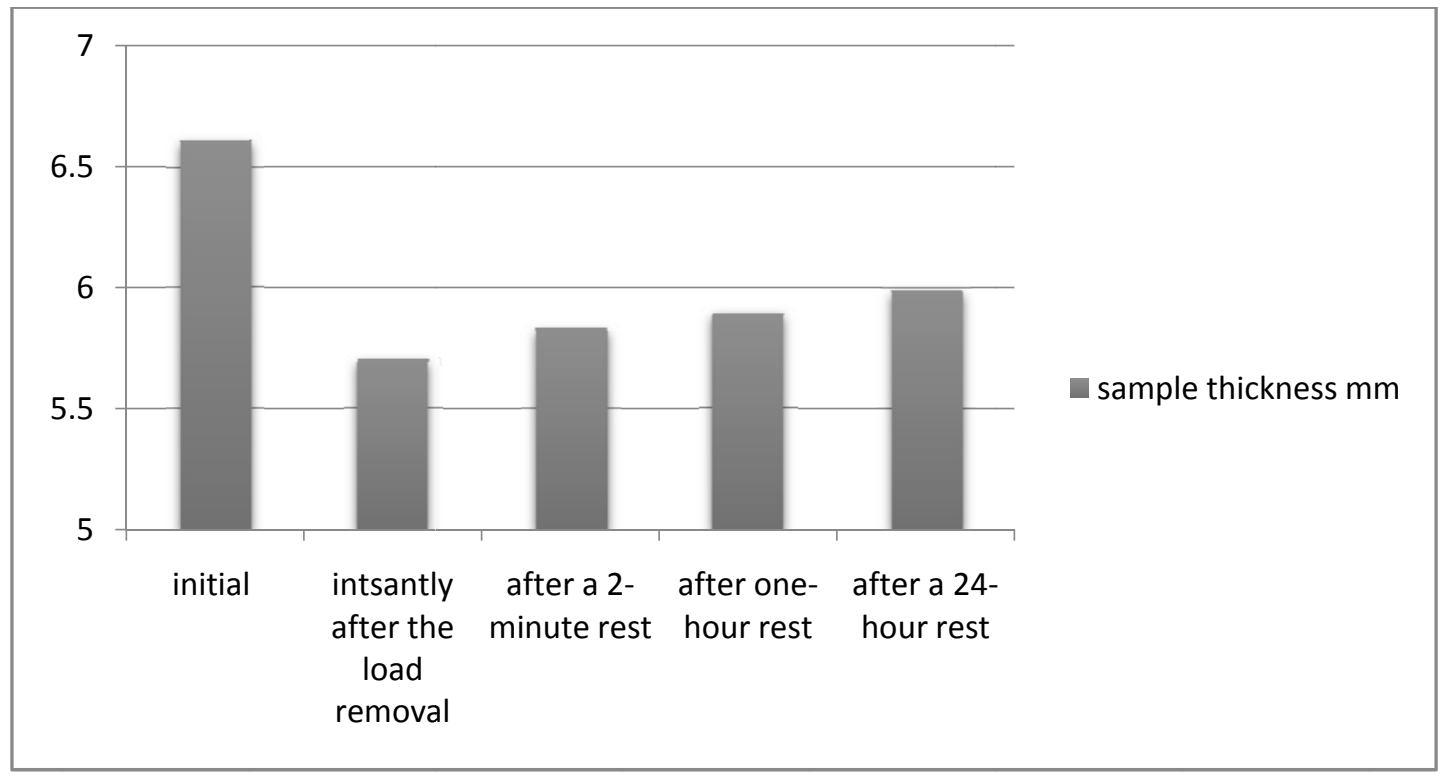

Chart 3-3: thickness measurement of Turkmen silk under the static load

The mean thickness of samples woven from the Turkmen silk was $6.61 \mathrm{~mm}$ prior to the experiment, which was decreased to $5.70 \mathrm{~mm}$ after the application of force for 24 hours. At this stage, $0.91 \mathrm{~mm}$ of the sample thickness was reduced (about 13.76\%). After two minutes of rest, the sample thickness was measured as $5.83 \mathrm{~mm}$, which means that $0.13 \mathrm{~mm}$ of the thickness was recovered, and the difference between the prior-to-experiment thickness and the current thickness reached to $0.78 \mathrm{~mm}$.

The mean thickness in the sample woven from the Turkmen silk reached $5.89 \mathrm{~mm}$ after one hour, which shows a $0.72 \mathrm{~mm}$ difference with the initial thickness. At this stage, $0.06 \mathrm{~mm}$ was added to the initial thickness, compared to the previous stage.

After 24 hours of rest, the sample thickness became $5.99 \mathrm{~mm}$, which was $0.1 \mathrm{~mm}$ higher than the previous stage thickness, and $0.62 \mathrm{~mm}$ lower than the initial thickness. Regarding the obtained means, it can be concluded that in these samples, about $0.62 \mathrm{~mm}$ (about 9.37\%) of the initial thickness has not been recovered.

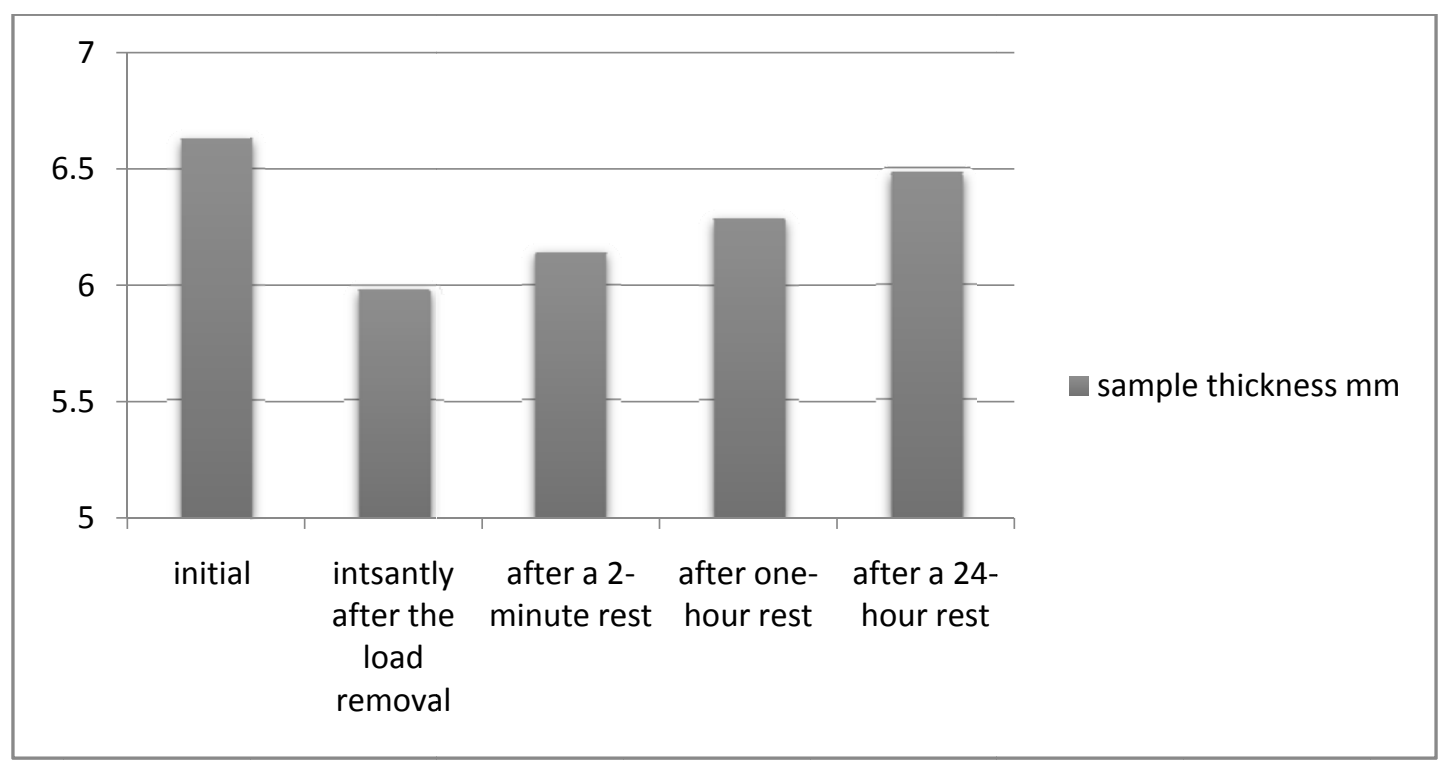

Chart 3-4: thickness measurement of Uzbek silk under the static load

The mean thickness of samples woven from the Uzbek silk was 6.63mm prior to the experiment, which was decreased to $5.98 \mathrm{~mm}$ after the application of force for 24 hours. At this stage, $0.65 \mathrm{~mm}$ of the sample thickness was reduced (about 9.80\%). After two minutes of rest, the sample thickness was measured as $6.14 \mathrm{~mm}$, which means that $0.16 \mathrm{~mm}$ of the thickness was recovered, and the difference between the prior-to-experiment thickness and the current thickness reached to $0.49 \mathrm{~mm}$. 
The mean thickness in the sample woven from the Uzbek silk reached $6.29 \mathrm{~mm}$ after one hour, which shows a $0.34 \mathrm{~mm}$ difference with the initial thickness. At this stage, $0.15 \mathrm{~mm}$ was added to the initial thickness, compared to the previous stage.

After 24 hours of rest, the sample thickness became $6.48 \mathrm{~mm}$, which was $0.19 \mathrm{~mm}$ higher than the previous stage thickness, and $0.15 \mathrm{~mm}$ lower than the initial thickness. Regarding the obtained means, it can be concluded that in these samples, about $0.152 \mathrm{~mm}$ (about 2.26\%) of the initial thickness has not been recovered.

Based on the charts of the results on the thickness of the samples after being under the static load, it was revealed that in all four types, we have seen a reduction in initial thickness. The Chinese silk sample had the highest resilience with a $1.8 \%$ difference with the initial thickness, and after it was the Uzbek silk with a $2.26 \%$ difference with the initial thickness, Iranian silk with a 3.15\% difference with the initial thickness, and the Turkmen silk with a 9.37\% difference with the initial thickness.

\section{3-2- Evaluation of the Samples Strength against the Dynamic Load:}

In this experiment, 3 samples were woven from each type of the silks and they were tested. Firstly, the initial sample thickness was measured. Then, the sample was placed under the related device and after the initial 50 hits, the sample was taken out, in order to its thickness to be measured. After every 50 hits, until 500 hits, the thickness was measured and noted down. The results of this experiment are provided in the table (3-2) and the charts 3-5, 3-6, 3-7, and 3-8.

Table 3-2: the sample mean thickness under the dynamic load

\begin{tabular}{|c|c|c|c|c|c|c|c|c|c|c|c|}
\hline Silk type & $\begin{array}{c}\text { Initial } \\
\text { thickness }\end{array}$ & 50 & 100 & 150 & 200 & 250 & 300 & 350 & 400 & 450 & 500 \\
\hline Iranian & $6 / 21$ & $5 / 95$ & $5 / 86$ & $5 / 64$ & $5 / 53$ & $5 / 48$ & $5 / 41$ & $5 / 37$ & $5 / 31$ & $5 / 24$ & $5 / 13$ \\
\hline Chinese & $6 / 58$ & $6 / 14$ & $5 / 87$ & $5 / 65$ & $5 / 52$ & $5 / 47$ & $5 / 42$ & $5 / 39$ & $5 / 36$ & $5 / 32$ & $5 / 25$ \\
\hline Uzbek & $6 / 12$ & $5 / 94$ & $5 / 78$ & $5 / 44$ & $5 / 34$ & $5 / 24$ & $5 / 15$ & $5 / 04$ & 5 & $4 / 93$ & $4 / 86$ \\
\hline Turkmen & $6 / 06$ & $5 / 39$ & $5 / 33$ & $5 / 22$ & $5 / 10$ & $5 / 04$ & $4 / 99$ & $4 / 94$ & $4 / 92$ & $4 / 89$ & $4 / 85$ \\
\hline
\end{tabular}

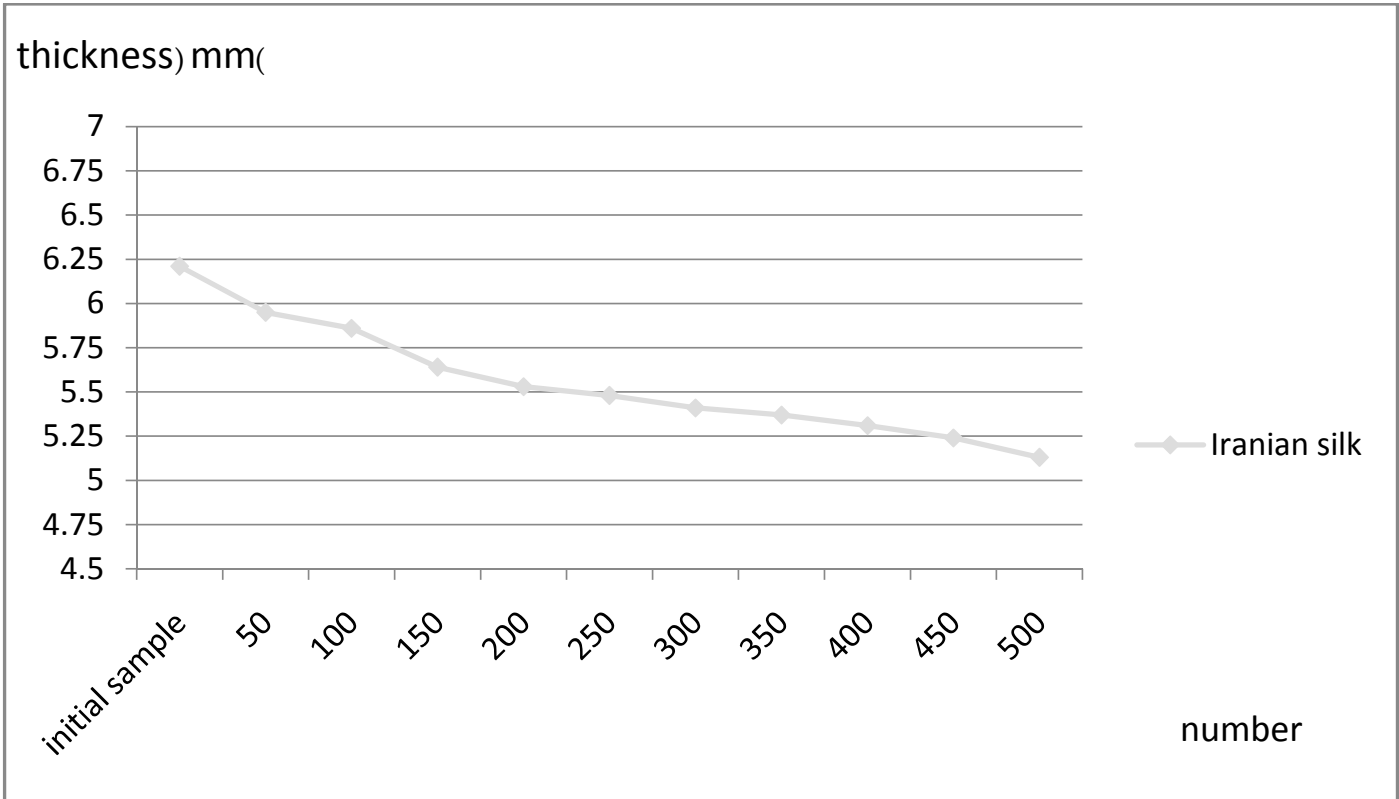

Chart 3-5: the thickness measurement of Iranian silk under dynamic load

The results of this experiment on the sample woven from the Iranian silk, indicate that mean initial thickness of this sample has been $6.21 \mathrm{~mm}$ prior to being under the dynamic load, and after application of the mobile load and 500 hits, its thickness has been reduced to $5.13 \mathrm{~mm}$. This reduction has been $17.4 \%$. 


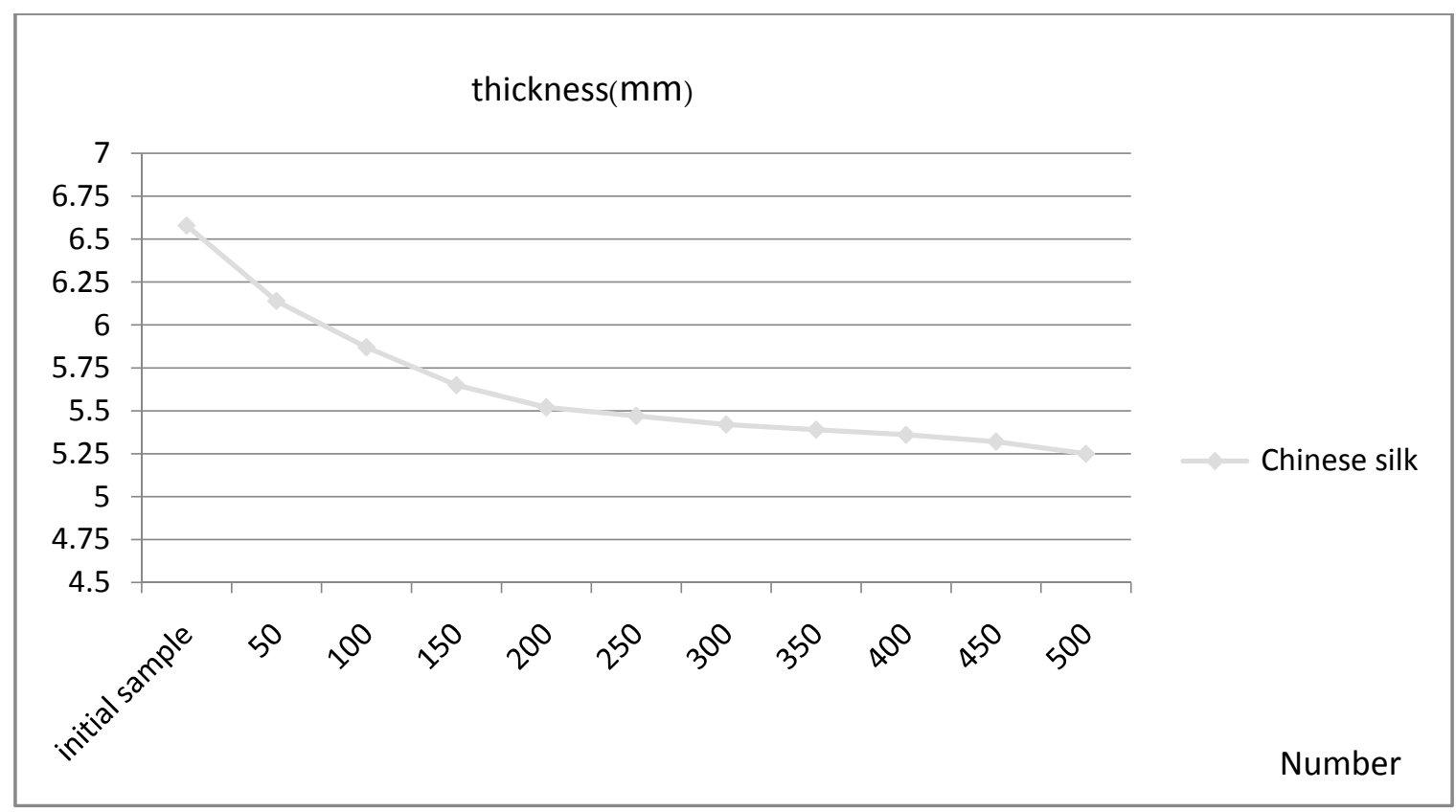

Chart 3-6: the thickness measurement of Chinese silk under dynamic load

The results of this experiment on the sample woven from the Chinese silk, indicate that mean initial thickness of this sample has been $6.58 \mathrm{~mm}$ prior to being under the dynamic load, and after application of the mobile load and 500 hits, its thickness has been reduced to $5.25 \mathrm{~mm}$. This reduction has been $20.22 \%$.

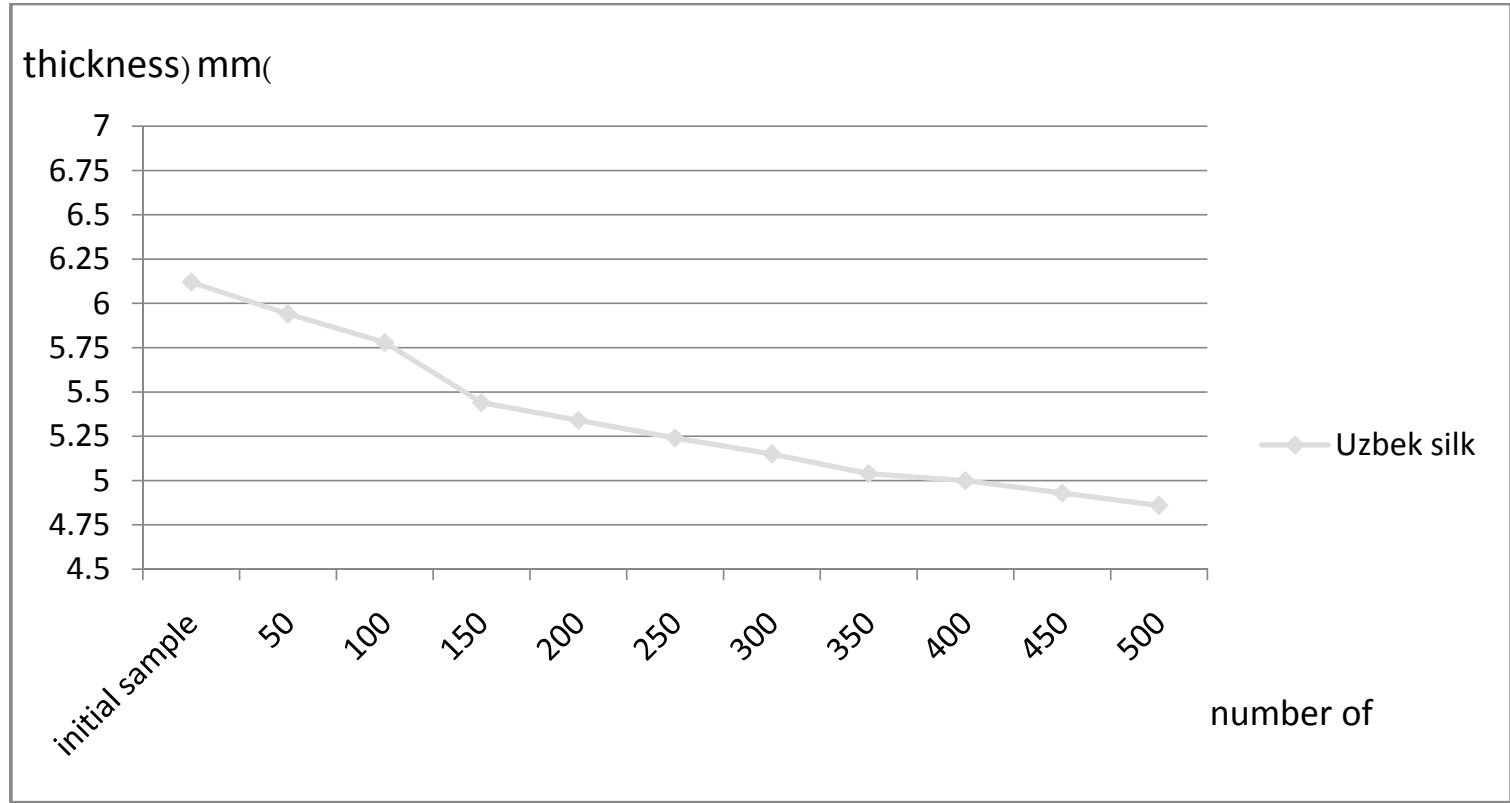

Chart 3-7: the thickness measurement of Uzbek silk under dynamic load

The results of this experiment on the sample woven from the Uzbek silk, indicate that mean initial thickness of this sample has been $6.12 \mathrm{~mm}$ prior to being under the dynamic load, and after application of the mobile load and 500 hits, its thickness has been reduced to $4.86 \mathrm{~mm}$. This reduction has been $20.59 \%$. 


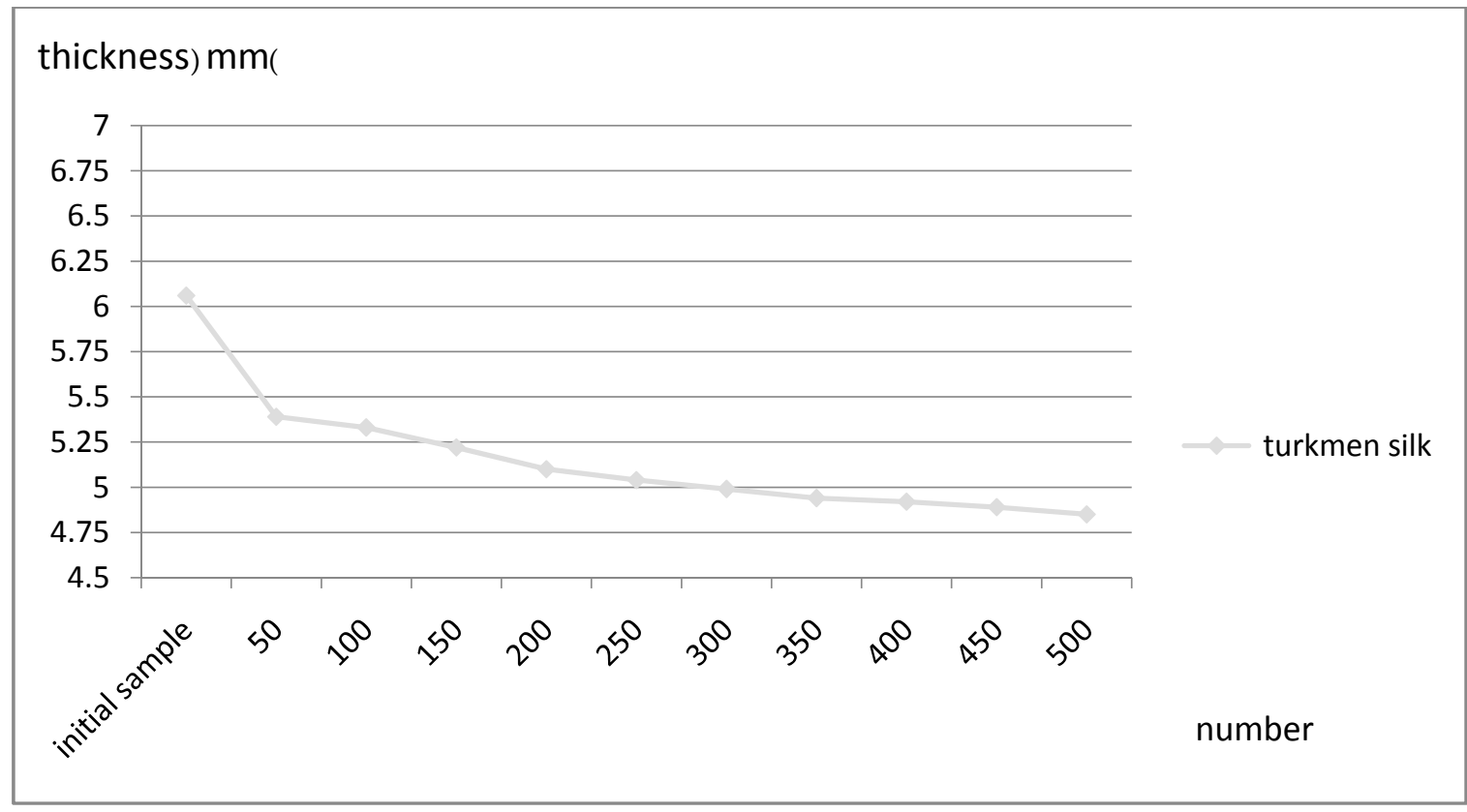

Chart 3-8: the thickness measurement of Turkmen silk under dynamic load

The results of this experiment on the sample woven from the Turkmen silk, indicate that mean initial thickness of this sample has been $6.06 \mathrm{~mm}$ prior to being under the dynamic load, and after application of the mobile load and 500 hits, its thickness has been reduced to $4.58 \mathrm{~mm}$. This reduction has been $19.97 \%$.

The results obtained from this experiment on the four types of silk thread show that the Iranian silk has had the lowest reduction in thickness under the dynamic load, with the Turkmen, Chinese, and Uzbek silks being after it with a narrow margin.

\section{Strength against Static Load:}

\section{4- General Conclusion:}

Based on the results obtained from the samples thickness changes after application of static load, it was revealed that all the four types of samples underwent a thickness reduction at the initial stage. The Chinese silk sample had the highest resilience with a 1.8\% difference with the initial thickness, and after that, were the Uzbek silk with a $2.26 \%$ difference with the initial thickness, Iranian silk with a 3.15\% difference with the initial thickness, and the Turkmen silk with a 9.37\% difference with the initial thickness.

\section{Strength against the Dynamic Load:}

The Iranian silk samples underwent a 17.4\% reduction compared to initial thickness, after application of 500 hits. The Turkmen silk samples underwent a 19.97\% reduction compared to initial thickness, after application of 500 hits. The Chinese silk samples underwent a 20.22\% reduction compared to initial thickness, after application of 500 hits. And the Uzbek silk samples underwent a 20.59\% reduction compared to initial thickness, after application of 500 hits.

Therefore, as it is seen, in terms of strength against the static load, the Chinese silk had the highest quality, and after it were Uzbek, Iranian, and Turkmen silks. But, in terms of the strength against dynamic load, the Iranian silk had the highest quality with Turkmen, Chinese, and Uzbek silks being after it.

\section{References:}

[1] Veisian, Seyyed Mohammad et al. (Degumming of Silk Yarn with Protease (Alkalase) and Comparing it with Keliab), Guljam Quarterly Journal, No. 8, p. 80

[2] Cooperation Journal, May, 2005, No. 164, p. 79

[3] Website of Tehran Chamber of Commerce, Industries, Mines and Agriculture.

[4] Dubinskaite, K \& et.al, "influence of pile Hight and density on end-use properties of carpets" Fibers\&Texiles in Eastern Europe. Vol 16, No3 (2008) 47-50.

[5] mirJalili, S.A. and sharzehec, m., " an investigation on the Effect of static and dynamic loading on the physical characteristics of handmade Persian carpet; part 1, the Effect of static loading”, J. T.I. Vol., 96, NO 5, (2005), 287-293. 10 1

[6] moghassem, A.R. \&gherehaghaji, A.A., "Evaluation pile yarn characteristics in Hand woven carpet using stress- strain behavior in compression”, l.J.E; Vol 21, NO.3 (2008), 303-312.

[7] 7- Koc, E., CeliaK, N \&Tekin. M, “An Experimental study on thiknes 0s loss of wilton- - type carpets production with Different pile materials after prolonged Heavy static Loading”, F.T.E.T, No.4 (2005), 56-62.

[8] Erdogan, U.H. "Effect of pile Fiber cross section shape on compression properties of poly propylene carpets", J.T.l, Vol, 103, No.12, (2012). 1369- 1375.

[9] carnaby.G.A.\& wood, E.J. (1981) “ the physics of carpets”, J.T.l, Vol. 80, No. I, pp. 71-90 
[10] Dubinskaite, K \& et.al. "influence of pile Hight and density on the End-use propertie, of carpets”, fibers \& Textiles in Easter Europe, vol 16, No 3 (2008).

[11] korkamz, Y\&Dalckocer, S. "Resilience behaviors of woven acrylic carpets under short-and long- term static loading”, J.T.l, Vol, 102, No 3. (2010). 236-241.

[12] Anonymous. "textile- The Hand-woven Woolen Carpets" (No. 1240), Institute of Standards and Industrial Research of Iran.

[13] Anonymous. "textile- Standard Environmental Conditions for Preparation and Testing" (No. 948), Institute for Standardization and Industrial Research of Iran

[14] Anonymous. "textile- A method for measuring the thickness of textile flooring" (No. 889), Institute of Standards and Industrial Research of Iran. 